BRAVZULIAN JOURNAL

OF MEDICAL AND BIOLOGICAL RESHARCH

www.bjournal.com.br
ISSN 0100-879X

Volume 44 (7) 606-728 July 2011

BIOMEDICAL SCIENCES

AND

CLINICAL INVESTIGATION

Braz J Med Biol Res, July 2011, Volume 44(7) 634-641

doi: 10.1590/S0100-879X2011007500070

Mechanisms of RON-mediated epithelial-mesenchymal transition in MDCK cells through the MAPK pathway

Xiangming Xu, Yun Qian, Guoliang Zhang, Jianjiang Lin and Lisong Teng

The Brazilian Journal of Medical and Biological Research is partially financed by

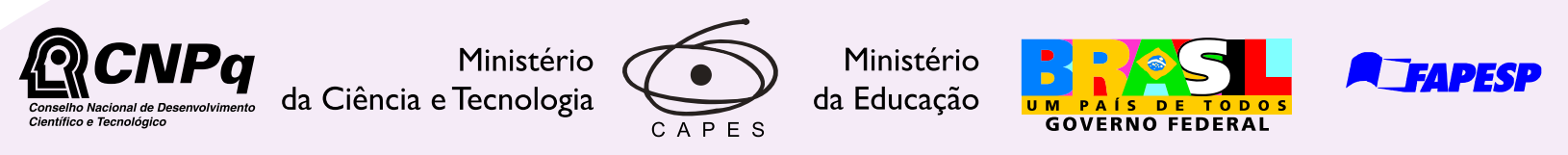

Institutional Sponsors
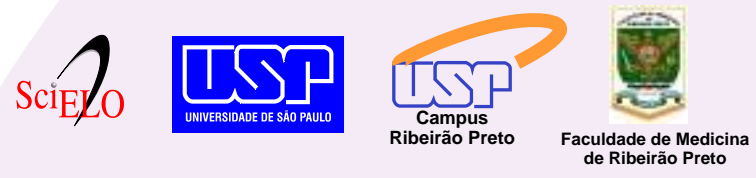
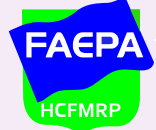

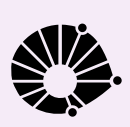

UNICAMP
Ф SHIMADZU

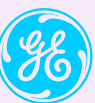

GE Healthcare
Hotsite of proteomics metabolomics developped by:

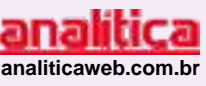




\title{
Mechanisms of RON-mediated epithelial-mesenchymal transition in MDCK cells through the MAPK pathway
}

\author{
Xiangming Xu1 ${ }^{1}$, Yun Qiann ${ }^{2,3}$, Guoliang Zhang ${ }^{1}$, Jianjiang Lin $^{1}$ and Lisong Teng ${ }^{4}$ \\ ${ }^{1}$ Colorectal Surgery, the First Affiliated Hospital, Zhejiang University School of Medicine, \\ Hangzhou, China \\ ${ }^{2}$ State Key Laboratory for Diagnosis and Treatment of Infectious Diseases, Institute of Infectious Diseases, \\ the First Affiliated Hospital, Zhejiang University School of Medicine, Hangzhou, China \\ Institute of Immunology, Zhejiang University, Hangzhou, China \\ ${ }^{4}$ Oncosurgery, the First Affiliated Hospital, Zhejiang University School of Medicine, Hangzhou, China
}

\begin{abstract}
The epithelial-mesenchymal transition (EMT) is involved in neoplastic metastasis, and the RON protein may be involved. In the present study, we determined the role and the mechanisms of action of RON in EMT in Madin-Darby canine kidney (MDCK) cells by Western blot and cell migration analysis. Activation of RON by macrophage stimulating protein (MSP) results in cell migration and initiates changes in the morphology of RON-cDNA-transfected MDCK cells. The absence of E-cadherin, the presence of vimentin and an increase in Snail were observed in RE7 cells, which were derived from MDCK cells transfected with wt-RON, compared with MDCK cells. Stimulation of RE7 cells with MSP resulted in increased migration (about $69 \%$ of the wounded areas were covered) as well as increased activation of extracellular signal-regulated kinase 1/2 (Erk1/2) and glycogen synthase kinase-3 $\beta$ (GSK-3 $\beta$; the percent of the activation ratio was $143.6 / 599.8 \%$ and $512.4 \%$, respectively), which could be inhibited with an individual chemical inhibitor PD98059 $(50 \mu \mathrm{M})$ specific to MAPK/ERK kinase (the percent inhibition was 98.9 and $81.2 \%$, respectively). Thus, the results indicated that RON protein could mediate EMT in MDCK cells via the Erk1/2 pathway. Furthermore, GSK-3 $\beta$ regulates the function of Snail in controlling EMT by this pathway.
\end{abstract}

Key words: RON; Epithelial-mesenchymal transition; MAPK; Erk

\section{Introduction}

Epithelial-mesenchymal transition (EMT) is a biologic process that allows a polarized epithelial cell, which normally interacts with the basement membrane via its basal surface, to undergo multiple biochemical changes that enable the epithelial cell to assume a mesenchymal cell phenotype. This, in turn, provides the cell with enhanced migratory capacity, invasiveness, and increased resistance to apoptosis (1). The completion of an EMT is signaled by the degradation of the underlying basement membrane and the formation of a mesenchymal cell that can migrate away from the epithelial layer from which it originated.

In EMT, epithelial cells acquire fibroblast-like properties and show reduced intercellular adhesion and increased motility. This process is associated with the functional loss of E-cadherin (2,3). In cancer, down-regulation of E-cadherin is the key step towards the invasive phase of carcinoma, and dominant transcriptional repression is largely responsible for the loss of E-cadherin expression (4-8).

The conversion of an epithelial cell into a mesenchymal cell requires alterations in morphology, cellular architecture, adhesion, and migration capacity. Increased expression of $\mathrm{N}$-cadherin and vimentin, nuclear localization of $\beta$-catenin, and increased production of transcription factors such as Snail1 (Snail), Snail2 (Slug), Twist, EF1/ZEB1, SIP1/ZEB2, and/or E47 that inhibit E-cadherin production are the commonly used molecular markers for EMT. Phenotypic markers of EMT include an increased capacity for migration and three-dimensional invasion, as well as resistance to anoikis/ apoptosis (9). Importantly, these developmental regulators can induce EMT in a non-developmental context and thereby have an important role in cancer and fibrosis.

The MET receptor tyrosine kinase was one of the first

Correspondence: Lisong Teng, Oncosurgery, the First Affiliated Hospital, Zhejiang University School of Medicine, 79 Qingchun Road, Hangzhou 310003, China. Fax: +86-571-8723-6582. E-mail: Xuxiangming1974@msn.com

Received December 28, 2010. Accepted May 18, 2011. Available online June 3, 2011. Published July 25, 2011. 
identified cell surface receptors that was able to stimulate scattering of epithelial cells. Activation of MET by its ligand, hepatocyte growth factor, enhances the migration of multiple cell lines in vitro. The RON protein is a typical receptor tyrosine kinase (RTK) belonging to the MET family $(10,11)$. Induction of RON phosphorylation and kinase activities can be achieved through ligand-dependent and -independent mechanisms (12). Binding of macrophage stimulating protein (MSP) to extracellular sequences of RON leads to receptor homo-dimerization, which is a typical example of ligand-induced RON activation $(13,14)$. Ligandindependent RON activation was observed in various physiological and pathological conditions (15-17). Aberrant RON expression also results in receptor phosphorylation and kinase activation (16-18), which contributes to the pathogenesis and malignancy of epithelial tumors.

The present investigation was undertaken to determine the role and the mechanisms of RON in EMT in MadinDarby canine kidney (MDCK) cells. Currently, the details of mechanisms underlying RON-mediated cell migration and shape change are unknown. Through a series of experiments, we demonstrated that RON could mediate EMT in MDCK cells through the Erk1/2 pathway. Thus, RON may be involved in tumor progression and metastasis.

\section{Material and Methods}

\section{Cell lines and reagents}

The MDCK cells derived from a kidney of an apparently normal adult female cocker spaniel were obtained from the American Type Culture Collection (ATCC, USA). RE7 cells, stably expressing RON as described previously (14), were derived from MDCK cells transfected with wt-RON. The rabbit anti-RON antibody (R5029) was a gift from Prof. Wang (Center for Biology Therapeutics, School of Pharmacy, Texas Tech University Health Sciences Center, USA). MSP was obtained from R\&D System (USA). PD98059 as an Erk1/2 inhibitor was purchased from Cell Signaling Technology (USA). Goat or rabbit lgG antibodies specific for Pan-Erk, phosphor-Erk1/2 (p44/42), E-cadherin, vimentin, Snail, Twist, regular or phosphor glycogen synthase kinase-3 $\beta$ (GSK-3 $\beta$ ) and AKT were purchased from Cell Signaling Technology (USA) and Santa Cruz Biotechnology (USA), respectively. Rabbit IgG antibodies (R5029) specific for human RON C-terminal peptides were used as previously described (19).

\section{Cell lysates}

All cells were lysed using cell lysis buffer (10X) containing $20 \mathrm{mM}$ Tris- $\mathrm{HCl}$, pH 7.5, $150 \mathrm{mM} \mathrm{NaCl}, 1 \mathrm{mM} \mathrm{Na}_{2}$ EDTA, $1 \mathrm{mM}$ EGTA, 1\% Triton, $2.5 \mathrm{mM}$ sodium pyrophosphate, 1 $\mathrm{mM}$ beta-glycerophosphate, $1 \mathrm{mM} \mathrm{Na}_{3} \mathrm{VO}_{4}$, and $1 \mu \mathrm{g} / \mathrm{mL}$ leupeptin (Cell Signaling Technology). Samples containing $1 \times 10^{6}$ cells were lysed in $200 \mu \mathrm{L}$ cell lysis buffer (1X) for $30 \mathrm{~min}$ at $4^{\circ} \mathrm{C}$. The insoluble material was then removed by centrifugation at $8000 \mathrm{~g}$ for $10 \mathrm{~min}$. The concentration of protein in each lysate was determined using a BCA protein assay kit (Pierce, USA) with bovine serum albumin as the standard.

\section{Western blot analysis}

Western blot was carried out using specific antibodies followed by goat anti-rabbit, or mouse IgG coupled with HRP (Santa Cruz). The reaction was developed with enhanced ECL reagents and analyzed with a VersaDoc Imaging system (Bio-Rad).

\section{Cell migration assays}

MDCK and RE7 cells were cultured in Dulbecco's modified Eagle's medium (DMEM) containing 10\% fetal bovine serum at $37^{\circ} \mathrm{C}$ in a humidified atmosphere containing $5 \% \mathrm{CO}_{2}$. When the cells reached $60-70 \%$ confluence in a $60-\mathrm{mm}$ dish they were cultured in serum-free DMEM for $24 \mathrm{~h}$. The cell monolayers were scored with a 200- $\mu \mathrm{L}$ plastic tip and then treated with $2 \mathrm{nM} \mathrm{MSP}$ and/ or $50 \mu \mathrm{M}$ PD98059. Cell migration into the wounded area was measured after $24 \mathrm{~h}$. During the migration assay, the cells were taken out of the incubator and placed under a Olympus 1 x 2-UCB microscope with a 100X objective. Pictures of fixed positions in the wounds were taken with a Q IMAGING Micropublisher 5.0 RTV that was mounted on the microscope. Subsequently, the wound area in each picture was determined by outlining the wound and measuring the area using the Image-Pro Plus 6.0 software. From the wound area, the average wound width could be obtained by dividing the area by the length of the region analyzed.

\section{Results}

\section{Increased morphological changes and cell migration in MSP-stimulated RE7 cells}

RON activation mediates various activities including cell shape change and migration. We tested the morphogenic effect of RON on RE7 cells. MDCK and RE7 cells $\left(1 \times 10^{4}\right.$ cells per well in a 6-well plate) were stimulated with $2 \mathrm{nM}$ MSP for $72 \mathrm{~h}$. The changes in cell morphology were recorded with a light microscope (Figure 1). The results showed that, upon stimulating cells with MSP for $72 \mathrm{~h}$, scatter-like activities were observed as judged by cell-cell dissociation in RE7 cells. Individual cell morphology was also altered dramatically, with elongated shapes and a rounded appearance. The appearance of scatter-like activities suggests that RON acts as a morphogenic factor for cells.

The effect of RON on cell migration was also determined in a wound-healing assay. Stimulation of cells with MSP resulted in increased RE7 cell migration (about 69\% of the wounded areas were covered) (Figure 2). Thus, RON induced morphological changes and cell migration in RE7 cells. 

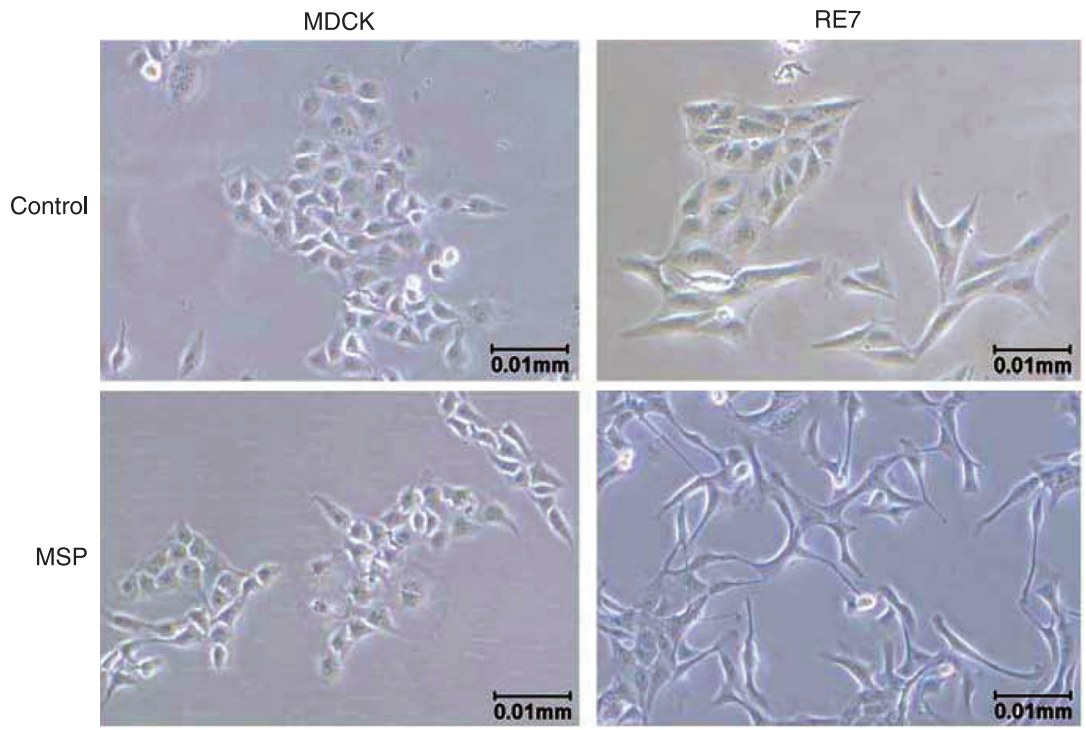

Figure 1. Morphological changes in macrophage stimulating protein (MSP)-stimulated RE7 cells. Cells $\left(1 \times 10^{4}\right.$ cells per well in a 6-well plate) were stimulated with $2 \mathrm{nM}$ MSP for $72 \mathrm{~h}$. The morphologic cell changes were recorded with a light microscope (100X). Upon stimulating cells with MSP for $72 \mathrm{~h}$, scatter-like activities were observed as judged by cell-cell dissociation in RE7 cells. Individual cell morphologies were also altered dramatically with elongated shapes and a rounded appearance.

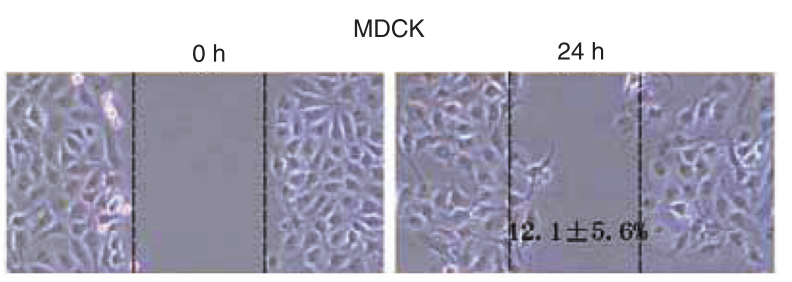

Control

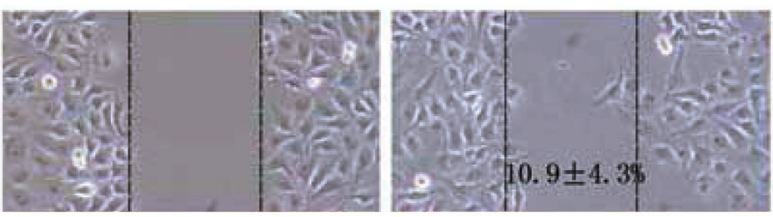

MSP

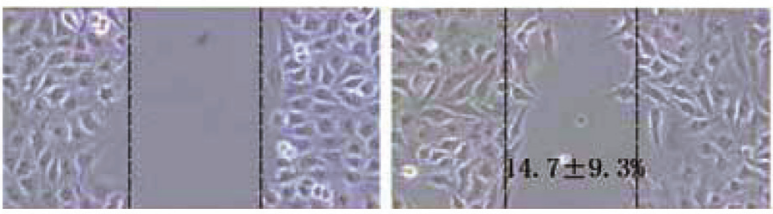

PD98059

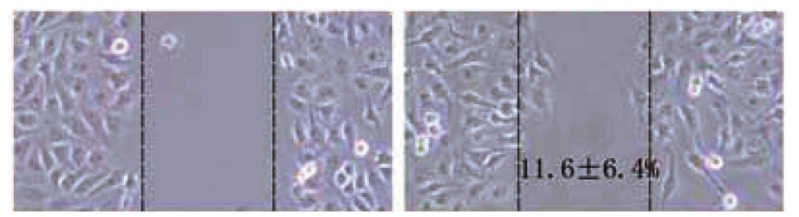

PD+MSP

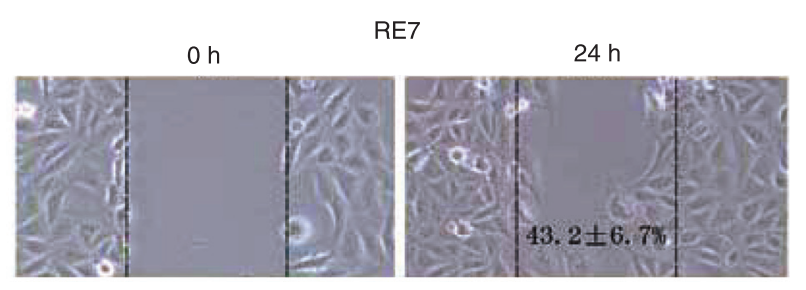

Control

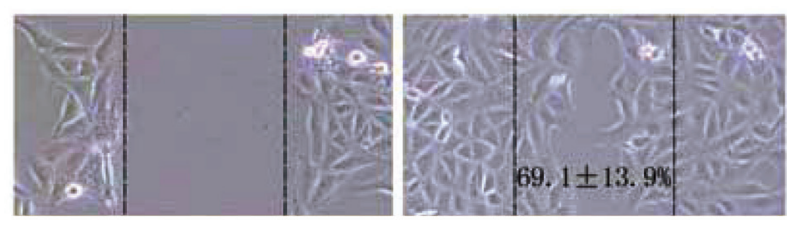

MSP

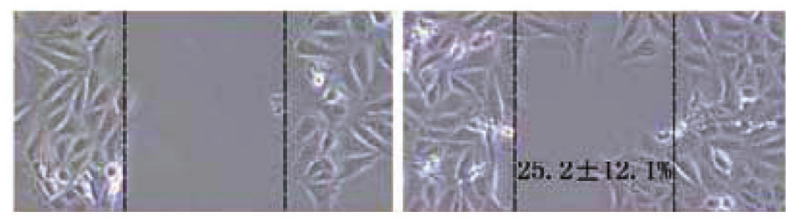

PD98059

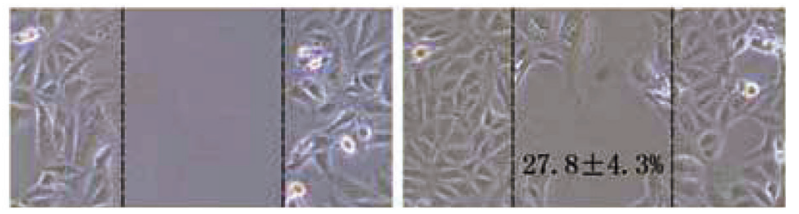

PD+MSP

Figure 2. Effect of RON activation on MDCK cell migration. Wounded spaces in cultures of MDCK and RE7 cells were created as detailed in the Material and Methods section. Cells were treated with $2 \mathrm{nM}$ macrophage stimulating protein (MSP) in the presence or absence of $50 \mu \mathrm{M}$ PD98059 (PD). The covered areas were calculated. Cell migration data are reported in the photos, which were taken at 0 and $24 \mathrm{~h}$ after incubation. Stimulation of cells with MSP resulted in increased RE7 cell migration, while PD98059 showed inhibitory effects on RE7 cell migration. 


\section{Induction of EMT and changes of related proteins induced by RON}

To determine whether RON had the ability to induce EMT in MDCK cells and to investigate the changes in RON-related proteins, cellular proteins from MDCK and RE7 cells were probed in Western blots with antibodies specific for RON, E-cadherin, vimentin, Snail, and Twist. The results are shown in Figure 3. The expression of RON in MDCK induced the expression of pro-RON, RON $\beta$-chain and $\mathrm{p} 110$. The absence of E-cadherin and the presence of vimentin was observed in RE7 cells. The expression of Snail was higher in RE7 than in MDCK. These results suggest that the presence of RON leads to induction of EMT and induces changes in RON-related proteins.

\section{The changes of signaling molecules in MSP-stimulated RE7 cells}

MSP-induced RON activation resulted in the in-

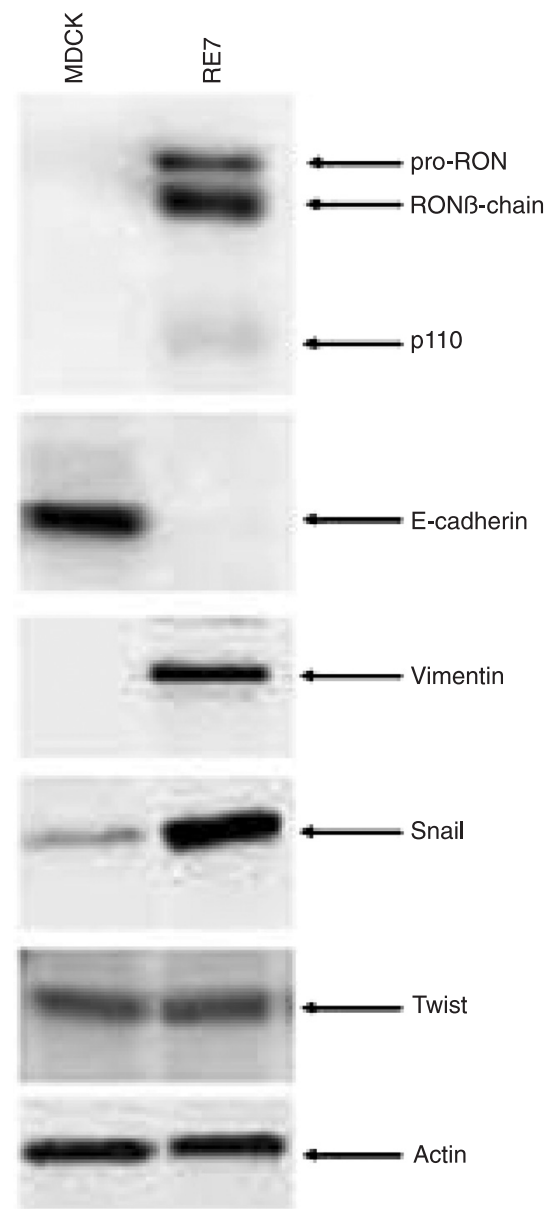

Figure 3. Induction of epithelial-mesenchymal transition and changes of related proteins by RON. Cellular proteins from MDCK and RE7 cells without any stimulation were probed in Western blots with five antibodies specific for RON, E-cadherin, vimentin, Snail, and Twist. creased activation of Erk1/2 and inactivation of GSK-3 $\beta$ in RE 7 cells compared with MDCK cells (the percent of the activation and inactivation ratio was Erk1 $=143.6 \%$, Erk2 $=599.8 \%$, and GSK-3 $\beta=512.4 \%$ ), but the activation of AKT and IKBa was not changed (Figure 4). The expression of Snail in 2 nM MSP-stimulated RE7 cells increased over time (from 0, 15, $30 \mathrm{~min}, 1,2$, and $6 \mathrm{~h}$; Figure 5), while the relative density ratio of Snail and $\beta$-actin increased from 0.428 to 1.333 . These results demonstrate that MSP-induced RON activation is capable of activating downstream signaling pathways such as Erk1/2 in RE7 cells.

\section{Inhibitory effect of PD98059 on MSP-stimulated RE7 cells}

To determine which signaling pathways are involved in enhanced cell migration and shape change, RE7 cells were stimulated with MSP in the presence of specific chemical inhibitors such as PD98059 (for Erk1/2), which is specific to MAPK/ERK kinase. PD98059 $(50 \mu \mathrm{M})$ inhibited MSPinduced activation of Erk1/2 (p44/42; Figure 6). The expression of phosphorylated GSK-3 $\beta$, Snail, and vimentin was decreased over time (from 0 to 15 and 30 min, and after 1 , 2 , and $6 \mathrm{~h}$ ). No change in cell signaling molecules was seen in cells treated with Wortmannin (data not shown).

In a wound-healing assay, stimulation of cells with MSP resulted in increased RE7 cell migration (Figure 2). PD98059 showed inhibitory effects on RE7 cell migration, inhibiting not only spontaneous migration, but also MSPinduced cell motility (about $25-28 \%$ of wounded areas were covered, respectively).

\section{Discussion}

We determined the role and the mechanisms of RON in EMT. RON activation transduces multiple signals that control cell replication, scattering, migration, and invasion of extracellular matrices (12). RON is involved in the EMT of MDCK cells. RON expression promotes transformation of cells from an epithelial phenotype to a mesenchymal phenotype. As shown in Figures 1 and 2, scatter-like activities with elongated shapes and a rounded appearance were observed in RE7 cells expressing RON, but not in normal MDCK cells. The phenotype of RE7 cells was different from that of MDCK cells, as shown by the absence of E-cadherin, the presence of vimentin, and up-regulation of Snail in RE7 cells relative to MDCK cells. Moreover, MSP stimulation induced cell migration (Figure 2), which suggests that activated RON transduces signals that activate the motile machinery of the cell, possibly playing a role in promoting invasive activity in vivo.

Our results also demonstrated that constitutive expression of RON in MDCK cells resulted in alterations of cell morphology with increased motile-invasive activities. These changes were characterized by the loss of epithelial markers 


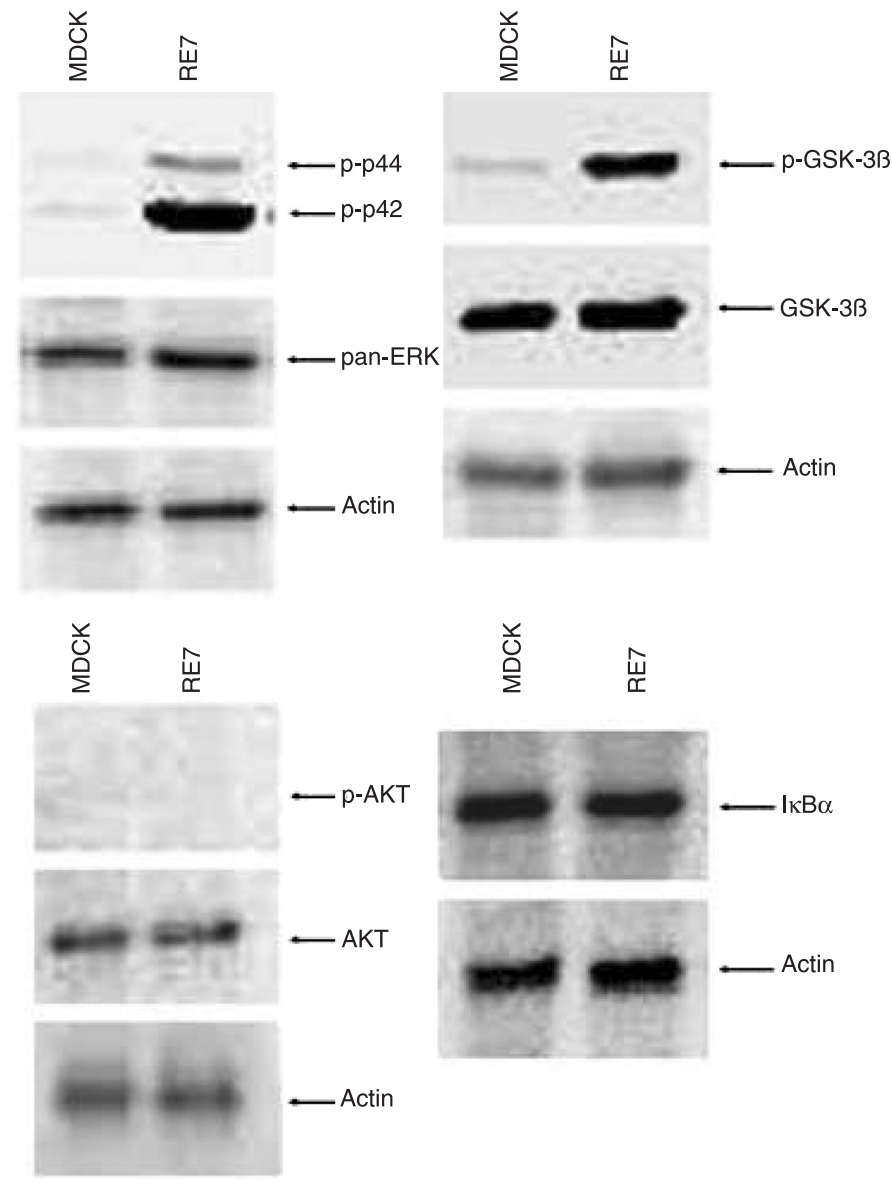

Figure 4. Changes of signaling molecules in macrophage stimulating protein (MSP)-stimulated RE7 cells. Cellular proteins from $2 \mathrm{nM}$ MSP-stimulated MDCK and RE7 cells were probed in Western blots using 5 antibodies specific

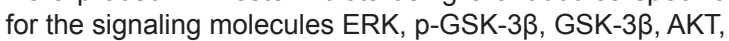
and IKBa.

RE7

\begin{tabular}{|c|c|c|c|c|c|c|}
\hline $0 \mathrm{~min}$ & $15 \mathrm{~min}$ & $30 \mathrm{~min}$ & $1 \mathrm{~h}$ & $2 \mathrm{~h}$ & $6 \mathrm{~h}$ & MSP \\
\hline
\end{tabular}

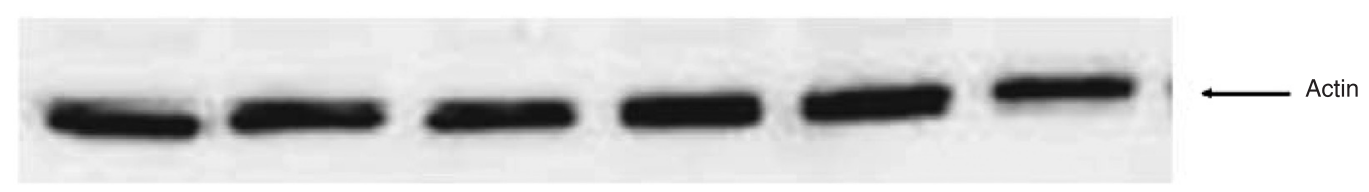

\begin{tabular}{ccccccc}
\hline Time & $0 \mathrm{~min}$ & $15 \mathrm{~min}$ & $30 \mathrm{~min}$ & $1 \mathrm{~h}$ & $2 \mathrm{~h}$ & $6 \mathrm{~h}$ \\
\hline $\begin{array}{c}\text { Density } \\
\text { ratio }\end{array}$ & 0.428 & 0.419 & 0.503 & 0.737 & 0.989 & 1.333 \\
\hline
\end{tabular}

Figure 5. Changes of Snail expression in macrophage stimulating protein (MSP)-stimulated RE7 cells. Cellular proteins from $2 \mathrm{nM}$ MSP-stimulated RE7 cells were probed in Western blots using 5 antibodies specific for Snail (from 0 , to 15 and $30 \mathrm{~min}$, and after 1, 2, and $6 \mathrm{~h}$ ). The expression level of Snail was shown by the relative density ratio of Snail and $\beta$-actin. 
such as adherent protein E-cadherin and the gain of mesenchymal phenotypes including the increased expression of vimentin.

The morphological changes mediated by RON are manifested through various signaling pathways such as Erk1/2 and AKT, thus altering cell adhesion, reorganizing the cytoskeleton, and reducing cellular interaction $(12,19)$. The expression of RON was accompanied by tyrosine phosphorylation, which indicated constitutive activation. MSP further regulated RON phosphorylation, leading to the activation of downstream signaling proteins such as Erk1/2 and GSK-3 $\beta$ (Figure 4). The results indicated that the activation of Erk1/2 stimulated with RON can lead to the increased expression of $p$-GSK$3 \beta$, in agreement with previous results $(20,21)$. It has been reported that MAPK can inactivate GSK-3 $\beta$ by direct phosphorylation at its $C$ terminus (21). Thus, the up-regulation of $p-G S K-3 \beta$ induced down-regulation of GSK-3 $\beta$ activation.

MSP-induced RON activation also enhanced the expression of Snail in a time-dependent manner (Figure 5), which was regulated by GSK-3ß. Snail was first identified in Drosophila, where it down-regulates the transcription of shotgun (an E-cadherin orthologue) to control gastrulation (3). Snail homologues have subsequently been found in many other species, including humans (3). Recently, Snail was shown to repress the expression of E-cadherin and to induce EMT in MDCK cells (22-24), which indicated that Snail has a fundamental role in EMT through its suppression of E-cadherin. Snail is a GSK-3 $\beta$ substrate, while inhibition of GSK-3 $\beta$ results in the up-regulation of Snail and down-regulation of E-cadherin in vivo (20).

Inhibition of MAP kinase activities by the specific chemical inhibitor PD98059 completely blocked cell migration. MSP-induced activation of Erk1/2 (p44/42) was inhibited by PD98059 (Figure 6). The expression of phosphorylated GSK-3 $\beta$, Snail, and vimentin was decreased over time. RE7 cell migration stimulated with MSP could also be inhibited by PD98059. Thus, the down-regulated expression of Snail inhibited by PD98059 indicated that it could function as a promoter for EMT, which was induced with Erk1/2 and reinforced the notion that cell migration and cancer metastasis are finely tuned events.
At present, the precise signaling pathways that transduce RON signals leading to EMT are largely unknown (19). However, the results shown here in Figures 4 and 6 provide important clues indicating that the activation of MAPK/Erk pathways might be critical. As shown in Figure 4, RON activation led to increased activation of Erk1/2, the constitutive components of the MAPK pathway. Blocking Erk1/2 activation by PD98059 might prevent the MSPinduced EMT with the decreased expression of vimentin. The regulation of Snail by GSK-3 $\beta$ reveals that many oncogenic pathways could govern human cancer cell invasion and metastasis by modulating GSK-3 $\beta$ activity. GSK-3 $\beta$ is a multi-tasking kinase involved in the Akt, Wnt, and Hedgehog pathways, all of which are engaged in the determination of cell fate and morphology (25). GSK-3 $\beta$ has been reported to bind and phosphorylate Snail and thereby induce its nuclear export (20). Therefore, the 
Erk1/2 oncogenic signals stimulated with RON inhibited GSK-3 $\beta$ and thus in turn resulted in the stabilization and nuclear localization of Snail to trigger cell migration and EMT. Since Snail regulates E-cadherin (26), we speculate that the down-regulation of GSK-3 $\beta$ by this pathway promoted and stabilized Snail and inhibited E-cadherin, to induce cell migration and lead to EMT.

Thus, our results indicate that RON could mediate EMT in MDCK cells. This occurred through the Erk1/2 pathway, which inhibited GSK-3 $\beta$, and in turn resulted in the stabilization of Snail and the down-regulation of E-cadherin.

\section{References}

1. Kalluri R, Neilson EG. Epithelial-mesenchymal transition and its implications for fibrosis. J Clin Invest 2003; 112: 17761784.

2. Thiery JP. Epithelial-mesenchymal transitions in tumour progression. Nat Rev Cancer 2002; 2: 442-454.

3. Nieto MA. The snail superfamily of zinc-finger transcription factors. Nat Rev Mol Cell Biol 2002; 3: 155-166.

4. Behrens J, Lowrick O, Klein-Hitpass L, Birchmeier W. The E-cadherin promoter: functional analysis of a G.C-rich region and an epithelial cell-specific palindromic regulatory element. Proc Natl Acad Sci U S A 1991; 88: 11495-11499.

5. Birchmeier W, Behrens J, Weidner KM, Frixen UH, Schipper J. Dominant and recessive genes involved in tumor cell invasion. Curr Opin Cell Biol 1991; 3: 832-840.

6. Hajra KM, Ji X, Fearon ER. Extinction of E-cadherin expression in breast cancer via a dominant repression pathway acting on proximal promoter elements. Oncogene 1999; 18: 7274-7279.

7. Ji X, Woodard AS, Rimm DL, Fearon ER. Transcriptional defects underlie loss of E-cadherin expression in breast cancer. Cell Growth Differ 1997; 8: 773-778.

8. Giroldi LA, Bringuier PP, de Weijert M, Jansen C, van Bokhoven A, Schalken JA. Role of $E$ boxes in the repression of E-cadherin expression. Biochem Biophys Res Commun 1997; 241: 453-458.

9. Hay ED. The mesenchymal cell, its role in the embryo, and the remarkable signaling mechanisms that create it. Dev Dyn 2005; 233: 706-720.

10. Ronsin C, Muscatelli F, Mattei MG, Breathnach R. A novel putative receptor protein tyrosine kinase of the MET family. Oncogene 1993; 8: 1195-1202.

11. Rubin JS, Bottaro DP, Aaronson SA. Hepatocyte growth factor/scatter factor and its receptor, the c-met proto-oncogene product. Biochim Biophys Acta 1993; 1155: 357-371.

12. Wang $M H$, Wang $D$, Chen $Y Q$. Oncogenic and invasive potentials of human macrophage-stimulating protein receptor, the RON receptor tyrosine kinase. Carcinogenesis 2003; 24: 1291-1300.

13. Gaudino G, Follenzi A, Naldini L, Collesi C, Santoro M, Gallo $\mathrm{KA}$, et al. RON is a heterodimeric tyrosine kinase receptor activated by the HGF homologue MSP. EMBO J 1994; 13: 3524-3532.

14. Wang MH, Ronsin C, Gesnel MC, Coupey L, Skeel A, Leonard EJ, et al. Identification of the ron gene product as

\section{Acknowledgments}

RE7 cells and the rabbit anti-RON antibody (R5029) were gifts from Prof. Wang (Center for Biology Therapeutics, School of Pharmacy, Texas Tech University Health Sciences Center, USA). This paper was proofread by a native English professional with a scientific background at Elixigen Corporation. Research supported by the National Natural Science Foundation of China for the Youth (\#30901425) and Medicine and Health Research Foundation of Zhejiang Province of China (\#200815390). the receptor for the human macrophage stimulating protein. Science 1994; 266: 117-119.

15. Danilkovitch-Miagkova A, Angeloni D, Skeel A, Donley S, Lerman M, Leonard EJ. Integrin-mediated RON growth factor receptor phosphorylation requires tyrosine kinase activity of both the receptor and c-Src. J Biol Chem 2000; 275: 14783-14786.

16. Follenzi A, Bakovic S, Gual P, Stella MC, Longati P, Comoglio PM. Cross-talk between the proto-oncogenes Met and Ron. Oncogene 2000; 19: 3041-3049.

17. Collesi C, Santoro MM, Gaudino G, Comoglio PM. A splicing variant of the RON transcript induces constitutive tyrosine kinase activity and an invasive phenotype. Mol Cell Biol 1996; 16: 5518-5526.

18. Zhou YQ, He C, Chen YQ, Wang D, Wang MH. Altered expression of the RON receptor tyrosine kinase in primary human colorectal adenocarcinomas: generation of different splicing RON variants and their oncogenic potential. Oncogene 2003; 22: 186-197.

19. Wang $D$, Shen $Q$, Chen $Y Q$, Wang MH. Collaborative activities of macrophage-stimulating protein and transforming growth factor-beta1 in induction of epithelial to mesenchymal transition: roles of the RON receptor tyrosine kinase. Oncogene 2004; 23: 1668-1680.

20. Zhou BP, Deng J, Xia W, Xu J, Li YM, Gunduz M, et al. Dual regulation of Snail by GSK-3beta-mediated phosphorylation in control of epithelial-mesenchymal transition. Nat Cell Biol 2004; 6: 931-940.

21. Thornton TM, Pedraza-Alva G, Deng B, Wood CD, Aronshtam A, Clements JL, et al. Phosphorylation by p38 MAPK as an alternative pathway for GSK3beta inactivation. Science 2008; 320: 667-670.

22. Batlle E, Sancho E, Franci C, Dominguez D, Monfar M, Baulida $\mathrm{J}$, et al. The transcription factor snail is a repressor of E-cadherin gene expression in epithelial tumour cells. Nat Cell Biol 2000; 2: 84-89.

23. Guaita S, Puig I, Franci C, Garrido M, Dominguez D, Batlle $\mathrm{E}$, et al. Snail induction of epithelial to mesenchymal transition in tumor cells is accompanied by MUC1 repression and ZEB1 expression. J Biol Chem 2002; 277: 39209-39216.

24. Cano A, Perez-Moreno MA, Rodrigo I, Locascio A, Blanco $M J$, del Barrio MG, et al. The transcription factor snail controls epithelial-mesenchymal transitions by repressing E-cadherin expression. Nat Cell Biol 2000; 2: 76-83. 
25. Doble BW, Woodgett JR. GSK-3: tricks of the trade for a multi-tasking kinase. J Cell Sci 2003; 116: 1175-1186.

26. Peinado H, Ballestar E, Esteller M, Cano A. Snail mediates
E-cadherin repression by the recruitment of the $\operatorname{Sin} 3 \mathrm{~A} /$ histone deacetylase 1 (HDAC1)/HDAC2 complex. Mol Cell Biol 2004; 24: 306-319. 